\title{
Adapting your teaching during the pandemic? How social science research education adapted to the COVID-19 pandemic
}

\section{Katrin Hasengruber, Matthias Forstner, Dimitri Prandner}

Department of Sociology - Empirical Research Unit, Johannes Kepler University of Linz, Austria.

\begin{abstract}
University lecturers worldwide had to adopt to online teaching at very short notice due to restrictions related to COVID-19. This is a particular challenge for social sciences research methods education, which often requires face-toface interactions.

Data from an online survey of lecturers ( $n=105$; March 2020) who teach social science methods and methodology at Austrian public universities was used to discuss their adaption behavior and the corresponding determinates. Consequently, a measure for the rate of adaption of teaching materials and methods per lecturer was constructed and a linear regression model employed to discuss the determinants of this adaption.

The results show the following: Understanding online teaching as a permanent solution for the future, the extent of an individual's teaching load and a tenured employment were identified as significant influences fostering the adaption of teaching methods and materials to the online context. The predictors discovered differ from previous studies, and it has to be assumed that the adaption behavior in the wake of the pandemic had a profound impact on the ongoing digitalization of university education.
\end{abstract}

Keywords: Social science research methods; digitalization; acceptance of distance teaching; adaption of online teaching. 


\section{Introduction - How Research and Methods Education Changed Overnight}

The devasting impact of the COVID-19 pandemic became obvious in the spring of 2020 and many educators had to instantaneously adapt their teaching style towards a new reality of online-based distance teaching. How far did such changes go? What could really be changed at short notice? And who was willing to adapt their lectures more substantially than others? Those questions are at the core of the following paper which tries to explain how Austrian social science educators responded to the pandemic in the summer semester 2020, as they had to readjust for online teaching and online courses over a few weeks. Despite the fact that this abrupt change has been an unusual experience in many ways (Watermeyer et al., 2020), it allows for the discussion of teaching pedagogy in a field of teaching that is typically defined by the fact that there is a canon on content that has to be taught, but that the teaching styles are highly dependent on individual experiences and personal relationships (Nind \& Lewthwaite, 2018).

The following section 2 illustrates the relevance of discussing research methods education, key aspects regarding the acceptance of online teaching before the pandemic struck and what may have influenced the changes in teaching in 2020. Afterwards, the data used will be described (3), before section 4 provides both insights into the changes in research methods teaching and potential explanations. A conclusion (5) closes the paper.

\section{Factors Influencing Changes and Innovations in Social Science Research Education}

Research methods education is a basic foundation of social science curricula as it provides students with the means to conduct primary research and distinguish between trustworthy empirical claims from invalid assertions (Wagner et al., 2011). Accordingly, it is not only one of the most employment-relevant aspects of the associated programs but also among the most challenging in university teaching for both students and lecturers (Earley, 2014; Wagner et al., 2011). It typically relies on in-person courses, often tied to in-person tutorials, group work and other interaction-intensive tasks, such as data collection (e.g. via interviews, faceto-face surveys), which are also typically part of social science research training (Michaelsen \& Sweet, 2008; Prandner \& Tabakovic, 2019). All these aspects were in conflict with Covid19 regulations issued during the early stages of the pandemic in most countries. Accordingly, this necessitated new pedagogical strategies in terms of teaching research methods. This is of relevance, as it made adapting - at least in some form - to distance learning via online tools necessary. However, this form of teaching is still highly contested in academia, with educators rejecting it, having a skeptical perspective on it or using it simply because of pragmatic reasons and only a few advocating for it altogether (Bolliger \& Martin, 2018; Zhang et al., 2020). 
Reasons for this are often tied to quality concerns, as online teaching is seen as timeconsuming and demanding in preparation, making adaptions hard especially when it comes to smaller, interactive classrooms where ongoing student evaluation and interaction are key (Zhang et al., 2020). Furthermore, previous publications illustrate that attitudes towards online teaching are highly dependent on institutional factors, as tenured faculty members, for example, are less likely to experiment with pedagogical strategies because they are already embedded in established institutional processes. Increased teaching load may also limit the potential for change or innovation in the teaching program (Bolliger \& Martin, 2018; Hogan \& McKnight, 2007). However, demographic analysis show that younger female educators are more open to teaching innovations than others (Horvitz et al., 2015). It can generally be argued that most of these effects may be tied to professional socialization and brings forward the question whether these factors also come into play when educators are forced to adapt their teaching content to an online teaching environment?

\section{The Dataset and the Methods Used}

The survey is part of the Digitize! initiative funded by the Austrian Federal Ministry for Education, Science and Research. It is meant to constantly monitor the digitalization of social science research methods education in Austria beginning in 2020. While the project was projected to start in mid-2020, the COVID-19 pandemic and its influence on universities forced the researchers to start in March 2020 and not to observe a field that may slowly adapt new teaching methods but one that radically transformed within a few months.

The population for the study was defined as university level educators, who teach either research-centric courses or method classes in one or more of the four core disciplines of the social sciences at public universities in Austria: Sociology, political science, communication studies and educational sciences. The corresponding individuals were identified via the online lecture lists that Austrian public universities maintain, resulting in a total population of 182 individuals who teach social science research courses or methods, of which 105 responded (response rate: $58 \%$ ). The questionnaire focused on structured questions designed to identify respondents' pedagogical strategies, feelings and experiences with online teaching and assessments. Additionally, it gathered context information and demographics (e.g. discipline, gender, years of experience, position). Two rounds of pretests precluded the start of the survey.

The items and scales used for this paper and their distribution can be found in Table 1, which also includes information on the distribution, dispersion and coding of the variables - this information is included to help understand the regression that follows in section 5 . The independent variables used are tied directly to the influences identified in section 2. 
Table 1. Independent Variables Used.

\begin{tabular}{|c|c|c|c|c|}
\hline & Dimension & Variable & Scale & $\begin{array}{l}\text { Mean (St. } \\
\text { Dev.) or } \\
\text { Percent }\end{array}$ \\
\hline \multirow{4}{*}{ 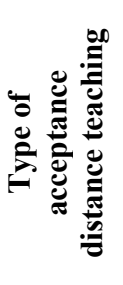 } & Advocates & Typology from the two & \multirow{4}{*}{$\begin{array}{l}\text { Two questions were } \\
\text { used to create four binary } \\
\text { variables. The variable } \\
\text { for each type was coded } \\
\text { as follows: } \\
1 \text { = Type assigned } \\
0=\text { Other type }\end{array}$} & 15.3 \\
\hline & Pragmatists & variables: & & 18.5 \\
\hline & Skeptics & Distance teaching is only & & 3.5 \\
\hline & Distanced & $\begin{array}{l}\text { a temporary solution \& } \\
\text { I will continue to } \\
\text { implement aspects of } \\
\text { online teaching after the } \\
\text { pandemic }(n=85)\end{array}$ & & 62.7 \\
\hline 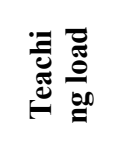 & $\begin{array}{l}\text { Lesson hours } \\
\text { per week }\end{array}$ & $\begin{array}{l}\text { How many teaching units } \\
\text { ( } 45 \text { min) did you teach per } \\
\text { week this semester? ( } \mathrm{n}= \\
\text { 98) }\end{array}$ & $\begin{array}{l}\text { numeric } \\
\text { (number of units) }\end{array}$ & $\begin{array}{c}4.45 \\
(3.27)\end{array}$ \\
\hline \multirow{2}{*}{ 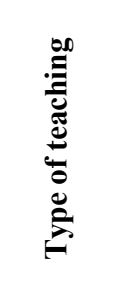 } & $\begin{array}{l}\text { Examination- } \\
\text { immanent } \\
\text { course }\end{array}$ & $\begin{array}{l}\text { Exclusively courses with } \\
\text { exercises, applications, } \\
\text { seminar or project } \\
\text { character } \\
(\mathrm{n}=105)\end{array}$ & \multirow{2}{*}{$\begin{array}{l}\text { Multiple choice } \\
\text { recoded into binary } \\
\text { variables } \\
1=\text { examination } \\
\text { immanent courses and } \\
\text { other courses } \\
0=\text { only examination } \\
\text { immanent courses }\end{array}$} & 76.2 \\
\hline & $\begin{array}{l}\text { Different } \\
\text { course types }\end{array}$ & $\begin{array}{l}\text { Lectures and courses } \\
\text { immanent to examinations } \\
(\mathrm{n}=105)\end{array}$ & & 11.4 \\
\hline 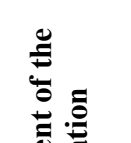 & $\begin{array}{l}\text { Perception of } \\
\text { additional } \\
\text { preparation }\end{array}$ & $\begin{array}{l}\text { I currently take longer } \\
\text { than normal to prepare } \\
\text { and follow up my lessons. } \\
(\mathrm{n}=91)\end{array}$ & $\begin{array}{l}\text { ordinal scales; recoded } \\
\text { into } 1=\text { 'strongly agree; } \\
\text { agree' and }\end{array}$ & 84.6 \\
\hline 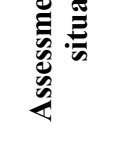 & $\begin{array}{l}\text { Interaction } \\
\text { with students }\end{array}$ & $\begin{array}{l}\text { I find interaction with } \\
\text { students via distance } \\
\text { learning is harder to } \\
\text { organize }(n=91)\end{array}$ & $\begin{array}{l}\text { disagree, disagree, } \\
\text { disagree strongly' to fit } \\
\text { linear regression }\end{array}$ & 56.0 \\
\hline \multirow{6}{*}{ 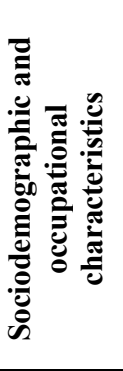 } & Female & $\begin{array}{l}\text { What gender are you? (n } \\
=89 \text { ) }\end{array}$ & \multirow{6}{*}{$\begin{array}{l}1=\text { female } \\
0=\text { male \& divers } \\
\text { numeric } \\
\text { (number of years) } \\
\text { External lecturer }\end{array}$} & 66.3 \\
\hline & Age & How old are you? $(\mathrm{n}=91)$ & & $\begin{array}{c}42.86 \\
(10.39)\end{array}$ \\
\hline & & & & 25.8 \\
\hline & Position & your current professional & & 19.4 \\
\hline & & position? $(\mathrm{n}=93)$ & & $\begin{array}{l}19.4 \\
35.4\end{array}$ \\
\hline & Tenure & $\begin{array}{l}\text { My current employment } \\
\text { contract is ... }(\mathrm{n}=94)\end{array}$ & & 28.7 \\
\hline
\end{tabular}

Source: Digitize! study on Methods Education Wave 1 (2020).

One of the central question batteries in this survey was used to identify how the classes were taught and how far individual educators adapted their teaching program (also see Figure 1 in section 4). This was used to calculate an adaption index, that will be used as the central dependent variable explaining how much an individual has actually adapted her/his teaching. The willingness to adopt to changes was used to create four groups of educators: Advocates, pragmatists, skeptics and distanced. Lecturers who thought that distance learning was a 
temporary solution and who will not continue form the type distanced. Those who do not consider distance learning to be an "emergency" solution but still do not want to use it in the future are called skeptics. Pragmatists are those who would like to continue using distance learning, despite seeing it as a temporary solution. The advocates include those who perceive distance learning as a permanent solution and are going to continue to use it. Additionally, the educators reported an average weekly teaching load of about four and a half teaching units each of 45 minutes. While the overwhelming majority of respondents state that preparing for online lectures takes more effort, only slightly more than half finds the interactions with students more cumbersome. Two-thirds of the sample are female and $20 \%$ are junior scientists. A majority has only a temporary contract.

\section{Six Days to Adjust Workshops, Research Projects and Tutorials to Online Teaching?}

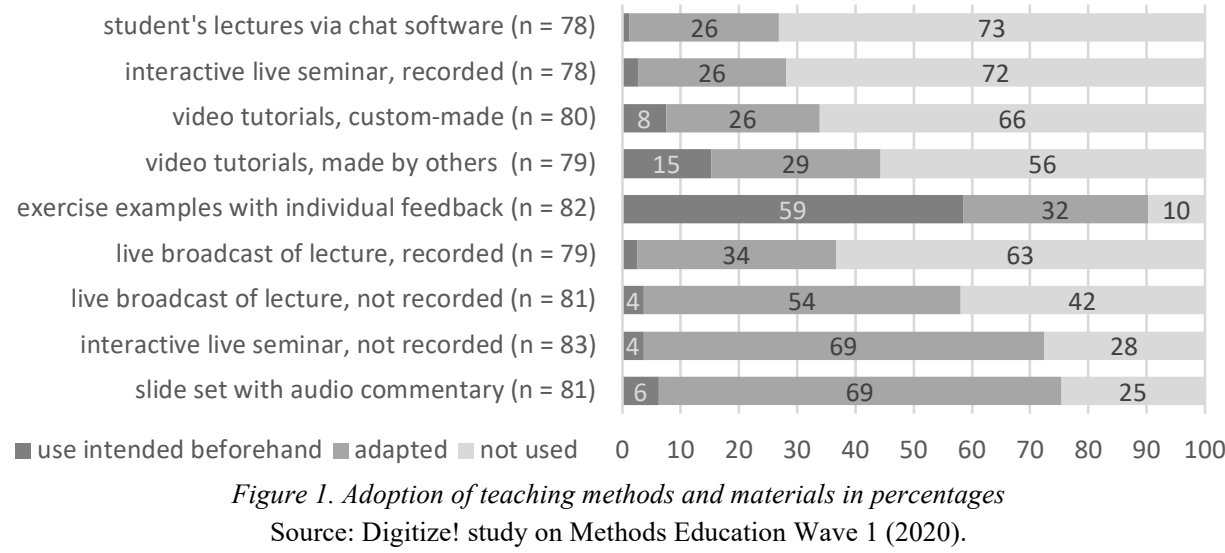

Only a few days into the summer semester of 2020 - on March 10 - most Austrian universities announced that they would shut down on-site lectures and courses for the foreseeable future, following a government-wide plan to stop the spread of COVID-19. However, teaching had to resume online on March 16 according to a federal issue. As neither students nor lecturers were prepared for this syllabi and course structures had to be rewritten on the fly, with no information on how long this shutdown may last. However, most lecturers could adapt quickly to a very specific situation and, as the survey results shows, many courses were adapted in extensive and significant ways (see Figure 1).

Accordingly, the most common strategies to deal with new demands without the chance to rely on preplanned solutions were adding audio commentary to slide sets, holding interactive online seminars and live broadcasting of lectures, however, without providing recordings. Tutorials or video presentations and lecture content prepared by students were employed rather seldom. Additionally, lecturers halved the number of exercises with individual 
feedback which is a traditional, proven strategy for research methods education (Prandner \& Tabakovic, 2019).

Furthermore, we also computed an indicator that could capture the extent of necessary didactic adaptions on an individual level: It relates the number of adapted teaching methods to the total number of methods that a lecturer used (see equation 1). This should give an insight into how much an individual tweaked their teaching style. The contractual obligations are introduced as weights to account for a potential bias coming from high or low teaching loads. They correspond with different academic jobs (e.g. research assistants, postdocs, assistant professors, full professors, senior lecturers). Those who teach fewer than 4 units per week (e.g. research associates, $\mathrm{PhD}$ students) receive a weight of 0.5 , while a load of 8 or more units have a weight of 1.5 (e.g. full professors, senior lecturers). Accordingly, the adaptation of teaching methods and materials ranges from 0 (no adaptation) to 1.5 (complete adaptation). The respondents $(\mathrm{n}=95)$ achieved an average value of 0.53 (standard deviation $0.36)$.

$$
\text { Extent of adaption }=\frac{\text { Number of teaching methods adapted }}{\text { Number of teaching methods used }} * \text { Weighting factor }
$$

\section{Explaining the Adaption of Teaching Methods and Materials}

We calculated a linear regression model to identify which factors help to explain the adaptation of teaching methods after the COVID-19 pandemic struck. It estimates the extent of adaption via the measures identified previously (see sections 2 and 3; for results, see Table 1). Due to the small number of cases, results with an alpha error below 0.1 are considered as (potentially) significant influences. Results need be read in accordance with those limitations.

As can be seen in Table 2, the attitude toward distance teaching influences to what extent teaching materials have been adapted. Instructors who plan to use online methods in the future (advocates) have a higher rate of adaption than those classified as distanced. Teaching load has the highest effect on adaption among the predicators considered. Due to the extent of the effect, it is reasonable to assume that it is not just related to the weighting of the adaption measures and that educators with a higher teaching load are significantly more likely to adapted their teaching to a higher extent than those with a lower. However, measures such as the acceptance type of distance teaching, the nature of the classes held or sociodemographic factors, such as age or gender, do not seem to influence the extent of adaption. Finally, the employment type is shown to be another central predictor for adaption, independently of the academic position (i.e. junior scientist, professor). Those who have a permanent contract - tenure - have adapted their teaching more than those without. This is an understandable result - a temporary employment is often associated with uncertainties and 
ambiguities as to what extent the teaching materials developed can be used again. It could also be argued that lecturers without the security of a permanent contract see themselves pressured into spending more time and resources on their research and, therefore, have fewer opportunities to adapt their teaching methods and material than staff who already have tenure.

Table 2. Linear Regression for the Extent of Adaptation. (Dep Var.: Adaption coefficient: 0 - 1.5; higher value equals a stronger adaption of teaching).

\begin{tabular}{lll}
\hline \multicolumn{1}{c}{ Independent Variables } & \multicolumn{1}{c}{ Std. Beta } \\
\hline $\begin{array}{l}\text { Type of acceptance of distance teaching (ref: } \\
\text { Distanced) }\end{array}$ & Advocates & $0.177 \sim$ \\
$\begin{array}{l}\text { Teaching load } \\
\text { Sociodemographic and occupational characteristics }\end{array}$ & $\begin{array}{l}\text { Lesson hours } \\
\text { per week } \\
\text { Tenure }\end{array}$ & $0.470^{* *}$ \\
$\mathbf{n}=$ & $0.281^{*}$ \\
$\mathbf{R}^{2}$ & 77 \\
\hline $\mathbf{p}<0.10 ; *$ p $<0.05 ; * * p<0.01 ;$ Only significant effects reported. There was no significent influence by type of \\
$\begin{array}{l}\text { acceptance of distance teaching: pragmatists, sceptics; type of teaching: examination immanent course, different } \\
\text { course types; assessment of the situation: perception of additional preparation, interaction with students, }\end{array}$ \\
$\begin{array}{l}\text { sociodemographic and occupational characteristics: female, age, job (ref: Professor): external lecturer, junior } \\
\text { scientist, mid-level position. Source: Digitize! study on Methods Education Wave 1 (2020). }\end{array}$
\end{tabular}

\section{Discussion}

The COVID-19 pandemic resulted in university professors worldwide having to adapt to online teaching practically overnight. In this paper, we could show that a large majority of lecturers - in our typology called distanced (69.7\%) - saw the changes as a temporary solution. Lecturers with a favorable disposition toward online teaching, however, were found to adapt more of their teaching methods and materials in the wake of the pandemic. Interestingly, all other factors being equal, lecturers who teach more hours per week also adapt more of their courses. This might be due to effects of scale, which make adapting a course easier for those who have already done it for another one. Additionally, lecturers who teach many courses might have felt more obliged to adjust to the situation than those who only teach a few. However, this finding disagrees with the position found in the literature that senior staff who have a higher teaching load are likely to be less prone to change or innovate their teaching programs (Bolliger \& Martin, 2018; Hogan \& McKnight, 2007). This discordance might indicate a difference in the adaption behavior before and in the wake of the pandemic. Another finding of our study was that lecturers adapted their teaching material and methods less if they only had a temporary employment contract. Thus, it might be the case that the uncertainties of a temporary academic job make instant adaptions of teaching methods to new circumstances more burdensome. Further studies could perhaps illuminate 
this. While previous studies have shown that younger and female academics are generally more open to the innovations of online teaching (Horvitz et al., 2015), no such influence could be detected in our data. This further indicates that with the sudden and mandatory pandemic-related changes in teaching modes, other factors are in play in determining adaption rates than previously.

\section{References}

Bolliger, D. U., \& Martin, F. (2018). Instructor and student perceptions of online student engagement strategies. Distance Education, 39(4), 568-583.

Earley, M. A. (2014). A synthesis of the literature on research methods education. Teaching in Higher Education, 19(3), 242-253. https://doi.org/10.1080/13562517.2013.860105

Hogan, R. L., \& McKnight, M. A. (2007). Exploring burnout among university online instructors: An initial investigation. The Internet and Higher Education, 10(2), 117-124.

Horvitz, B. S., Beach, A. L., Anderson, M. L., \& Xia, J. (2015). Examination of faculty selfefficacy related to online teaching. Innovative Higher Education, 40(4), 305-316.

Michaelsen, L. K., \& Sweet, M. (2008). The essential elements of team-based learning. New Directions for Teaching and Learning, 2008(116), 7-27. https://doi.org/10.1002/tl.330

Nind, M., \& Lewthwaite, S. (2018). Methods that teach: developing pedagogic research methods, developing pedagogy. International Journal of Research \& Method in Education, 41(4), 398-410. https://doi.org/10.1080/1743727X.2018.1427057

Prandner, D., \& Tabakovic, A. (2019). Measuring which support systems really work to improve students learning in your class - A case study on quantitative methods courses in the social sciences. 5th International Conference on Higher Education Advances (HEAd'19). Valencia: Universitat Politècnica València. https://doi.org/10.4995/HEAd19.2019.9133

Wagner, C., Garner, M., \& Kawulich, B. (2011). The state of the art of teaching research methods in the social sciences: towards a pedagogical culture. Studies in Higher Education, 36(1), 75-88. https://doi.org/10.1080/03075070903452594

Watermeyer, R., Crick, T., Knight, C., \& Goodall, J. (2020). Covid-19 and digital disruption in UK universities: Afflictions and affordances of emergency online migration. Higher Education, 81, 623-641. https://doi.org/10.1007/s10734-020-00561-y

Zhang, W., Wang, Y., Yang, L., \& Wang, C. (2020). Suspending classes without ltopping Learning: China's education emergency management policy in the COVID-19 outbreak. Journal of Risk and Financial Management, 13(3), 55. 